\title{
El monasterio premostratense de Santa María de La Vid durante los siglos XIV y XV: formas de explotación del dominio*
}

\author{
The Premonstratensian Monastery of Santa María de La Vid \\ during the Fourteenth and Fifteenth Centuries: Forms of Domain \\ Management
}

\author{
M. ${ }^{\text {a }}$ Teresa Angulo Fuertes ${ }^{* *}$
}

\begin{abstract}
RESUMEN
En el presente artículo analizamos la evolución de las formas de explotación del dominio de un importante monasterio premostratense castellano, el de Santa María de La Vid, durante la baja Edad Media. En el siglo XV cambia la dinámica económica del cenobio que pasa de administrar directamente sus granjas a darlas a censo enfitéutico, bien a particulares, bien a los concejos de los lugares en los que se encontraban ubicadas. Se analizan las razones de este cambio y se compara esta evolución con la de otros monasterios y conventos peninsulares así como las razones que los diferentes estudiosos señalan para esta transformación en la forma de organización económica de los cenobios mencionados.
\end{abstract}

\section{PALABRAS CLAVE}

Santa María de La Vid, Prémontré, monasterio, organización económica.

\begin{abstract}
This article examines the evolution of various forms of domain management by an important Castilian Premonstratensian monastery, Santa María de la Vid, during the late Middle Ages. During the fifteenth century an important economic shift takes place as the monastery relinquishes direct management of its domains and leases the land through emphyteutic tenure either to individuals, or to the town councils located near their land. The reasons for this change will be examined. Morevoer, the development of this phenomenon will be compared to that of other Peninsular monasteries and convents. Finally, the motives given by specialists for the shift in economic organization of these monasteries will be assessed.
\end{abstract}

\section{KEY WORDS}

Santa María de La Vid, Prémontré, Monastery, Economic Organization.

* Fecha de recepción del artículo: 2013-12-2. Fecha de aceptación del artículo: 2014-1-27.

** Doctoranda en el Departamento de Historia Medieval y Ciencias y Técnicas Historiográficas. UNED. C.e: anfuerco@gmail.com 
El monasterio de Santa María de La Vid, uno de los principales establecimientos de la Orden del Premontré en la Península, surge a mediados del siglo XII. En 1152, Alfonso VII y el infante Sancho confirman la donación del lugar de La Vid que el obispo de Osma, don Juan, había hecho a la iglesia de Monte Sacro y a su abad, Domingo, para construir una abadía bajo la regla de san Agustín. El nuevo monasterio acogerá al convento de Monte Sacro bajo la dirección del abad Domingo que aparece indistintamente en los documentos como abad de Monte Sacro o abad de La Vid. Su desarrollo se verá beneficiado durante la Edad Media por los diferentes monarcas castellanos y especialmente, por la casa de los Lara, hasta iniciar una época de decadencia en los años posteriores que terminará con su desaparición en el siglo XIX.

En el Archivo Histórico Nacional se custodia la mayoría de la documentación del monasterio de La Vid si bien en el archivo vitense se encuentra una importante fuente de información: el llamado «Tumbo de La Vid». Se trata de un códice manuscrito que fue comenzado en 1727 y cuyas últimas anotaciones datan de 1734. En él aparecen referencias a libros becerro anteriores que no se han conservado. El Tumbo consta de 486 folios y presenta un índice topográfico de documentos que siguen un orden alfabético, refiriendo en cada pueblo o lugar los documentos en los que consta que el monasterio tuvo propiedades. Se diferencian varias manos en el texto pero la mayoría se debe a un escriba que realiza una breve introducción al documento que unas veces transcribe y otras resume. Asimismo, el Tumbo contiene notas marginales, aclaraciones y llamadas de atención.

El estudio de este dominio monástico revela un cambio radical de la dinámica económica en 1400, año a partir del cual La Vid pasa de gestionar de manera directa las granjas monásticas, mediante canónigos, a la gestión indirecta a través de la constitución de censos enfitéuticos con particulares o concejos. El examen de esta circunstancia nos lleva a analizar el modo de gestión de otros monasterios situados en el mismo ámbito geográfico que el de La Vid, independientemente de la orden monástica de pertenencia, para verificar que se trata de un cambio de modelo de gestión generalizado en los casos analizados, y a señalar las razones de este cambio que los diferentes investigadores de los dominios monásticos establecen en sus estudios ${ }^{1}$.

\footnotetext{
1 VALLEJO, Juan José, «El monasterio de Santa María de la Vid. Fundación, formación y consolidación del señorío abacial. Colección diplomática (1132-1299)», en MARÍN DE SAN MARTíN, Luis, O. S. A (Coord.), El monasterio de la Vid, 850 años. Madrid, Religión y Cultura, 2004, pp. 99-240; BACKMUND, Norbert, «La Orden Premonstratense en España», en Hispania Sacra, 1983, pp. 57-85; SABATÉ, Flocel, «Los premonstratenses: creación de la orden e inicial expansión ibérica», en Entre el claustro y el mundo. Canónigos regulares y monjes premonstratenses en la Edad Media, Fundación Santa María la Real, Aguilar de Campoo (Palencia), 2009, pp. 127-162.
} 


\section{LA ORGANIZACIÓN ECONÓMICA DEL DOMINIO MONÁSTICO DE SANTA MARÍA DE LA VID}

El dominio monástico se forma a través de donaciones de sus benefactores y compras de heredades en las cercanías del cenobio durante los años siguientes ${ }^{2}$. Los premostratenses explotan estas heredades a través de establecimientos secundarios que dependen de la casa principal y que organizan los bienes y rentas de las zonas en que estaban ubicados; la gestión de las heredades de las que disponen se realiza de manera directa mediante granjas, al estilo cisterciense ${ }^{3}$. Las granjas premostratenses eran unidades agrarias dependientes del monasterio al que pertenecían, dedicadas a la explotación directa de las heredades adscritas mediante la agricultura, la ganadería u otras actividades económicas. Tenían que estar separadas unas de otras al menos una legua, tanto si eran de la misma o de diferente orden, para evitar disputas y conflictos. Dirigía y administraba la granja un canónigo delegado del monasterio denominado preboste o provisor, en contacto directo con el administrador del monasterio del que dependía y al que debía rendir cuentas. Periódicamente las granjas recibían inspecciones efectuadas por un canónigo que las visitaba. Estas unidades productivas eran autónomas económicamente y estaban a cargo de los llamados hermanos conversos, que como en el caso cisterciense, se consideran religiosos de inferior condición, encargados de los trabajos manuales y con formas de vida e incluso de oración diferentes a los canónigos ${ }^{4}$. Los hermanos conversos que residían en las granjas tenían en común el rezo del oficio cada mañana y semanalmente se reunían ante el provisor en un capítulo de faltas. En cada granja había una iglesia que en muchas ocasiones se convirtió en parroquia y reunió a su alrededor un hábitat rural que con el paso del tiempo dio origen a aldeas y pueblos.

${ }^{2}$ La organización de las actividades económicas de los premostratenses ha sido estudiada por Ghislain Brunel que circunscribe su estudio a la región de Soissons (Francia) en los siglos XII y XIII y que concluye que no hay un modelo económico premostratense único y por lo tanto, válido para todos los cenobios de la Orden. BRUNEL, Ghislain, «Les activités économiques des prémontrés en Soisson-

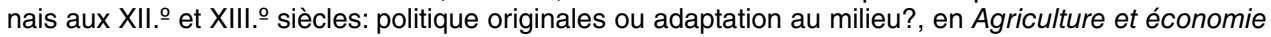
chez les prémontrés, Actes du $14 .^{\circ}$ colloque prémontré, 1988, Laon, Centre d'études et de recherches prémontrés, Amiens, 1989, pp. 66-79.

3 ALFONSO ANTÓN, Isabel, «Las granjas de Moreruela. Notas para el estudio de la colonización cisterciense en la Meseta del Duero (siglos XII-XIV)» en Semana de Historia del Monacato CántabroAstur-Leonés, Monasterio de San Pelayo, Oviedo, 1982, pp. 361-376.

4 VAN DEN BROECK, G., «Les frères convers dans la legislation des Prémontrés» en Analecta Praemonstratensia, XLIV, 1968, pp. 215-246. El monasterio de Monte Sacro era dúplice en su origen; a mediados del siglo XII el Capítulo General de Premontré ordenó la separación por lo que era necesario establecer una fundación para las religiosas. Una donación de los señores de Brazacorta permitirá establecer el priorato en este término. Desde finales del siglo XII y hasta su desaparición dos siglos más tarde, el priorato de Brazacorta, dependiente del monasterio de la Vid, se mantendrá gracias a la explotación de las granjas de Villapirle, Villafarre y Alcoba de Frandovínez, las tres situadas en las inmediaciones de Brazacorta. Así parece ser en el caso del monasterio de Santa María de Aguilar de Campoo en el que todas sus granjas parten de un cenobio previo que se une a su dominio. PÉREZ RODRíGUEZ, Francisco Javier, «Los monasterios premostratenses en los reinos occidentales de la península Ibérica, en Entre el claustro y el mundo. Canónigos regulares y monjes premostratenses en la Edad Media, Fundación Santa María la Real, Aguilar de Campoo, 2009, pp. 163-205. 
Los primeros datos sobre las granjas del monasterio de La Vid aparecen en la bula del papa Alejandro III que recibe bajo su protección al monasterio en 1163, confirmando las donaciones que el mismo había recibido muy pocos años antes, por lo que la conversión de las heredades en granjas se hizo rápidamente ${ }^{5}$. En ella se mencionan las granjas de Zuzones, Cubillas, Alcoba de Brazacorta, Villapirle, Lomeda y Torre del Rey.

Durante el siglo XIII se prolonga la formación del dominio del monasterio a través de donaciones y compras, si bien desciende el número de operaciones efectuadas. Frente al siglo anterior, el siglo XIII va a ser un periodo de crecimiento lento, con algunas menciones significativas a la pobreza del monasterio en algún documento, que se contradice con la realización de compras en esos mismos años. La organización económica seguirá siendo directa mediante granjas independientes, si bien aparecen ya algunos arrendamientos de heredades en los que las razones que los motivan no son únicamente económicas. Así en 1222 el abad Esteban otorga en empréstito las posesiones del monasterio en Hontoria a García Ordóñez y a su mujer, Urraca Bermúdez, con obligación de pagar el diezmo de lo que esas heredades produjeran al monasterio. A cambio, ellos donan las viñas que tenían en Hontoria, el derecho a apacentar los ganados del monasterio en Quemada, los collazos de Torregalindo y 700 mrs, también por este documento se convertían en familiares del monasterio de La Vid ${ }^{6}$. Otro contrato se produce en 15 de septiembre de 1285 en virtud del cual el monasterio arrienda a Ruy Díaz, sacristán de Valladolid, una heredad alejada de La Vid, situada en Dehesa de Revilla por un periodo de quince años con una renta anual de 150 mrs, comprometiéndose el arrendador a dar tres procuraciones anuales al abad y acompañantes en sus visitas?.

Durante el siglo XIV el monasterio continúa la explotación directa de sus heredades a través de sus granjas aunque con objeto de mejorar sus rendimientos,

\footnotetext{
${ }^{5}$ «... Ex dono videlicet Aldefonsi illustris memorie Hispaniarum Regis et concessione venerabilis fratris nostri lohannis Oxomensis episcopus locum in que Abbatia ipsa fundata est, cum omnibus pertinentiis suis. Grangiam de Suzones cum pertinentiis suis. Grangiam de Couelas cum pertinenciis suis. Grangiam que dicitur Alcoba de Brazacorta cum pertinentiis suis. Grangiam que dicitur Vilapirrle cum pertinentiis suis. Domos quas habetis in Ribelo cum earum pertinentiis, domum quam habetis in Cauanas cum pertinentiis suis. Domum quam habetis in Acetorres cum pertinentiis suis. Monasterium Beate Marie de Tortoles cum pertinentiis suis. Ecclesiam Sancti luliani del Olmo cum pertinentiis suis. Ex dono Petro lohannis Domum in Maderol cum pertinentiis suis. Et grangiam que dicitur Lumpnera cum salinis prope Metinam cum pertinenciis. Grangiam in Talamanca que dicitur Turris Regis cum pertinentiis suis...» Archivo Monasterio de La Vid (AMV), Tumbo de La Vid, cod. 2, fols. 230-231.

${ }^{6}$ Archivo Histórico Nacional (AHN), Clero, carp. 380, n.ำ 1. La Orden de Premontré distinguía entre sacerdotes, conversos y donados: «... tres maneras de religiosos; los sacerdotes o los que estudian para ello. La segunda es los conuersos que tanbien traen habito e aprenden las cosas del choro pero no son obligados a rezar el oficio diuino como los sacerdotes o los que estan para ello avnque traen el mismo abito. La tercera es los donados que deben traer el abito pardo mas no corona y estos tanbien los vnos como los otros an de hazer profesion de los votos». Biblioteca Nacional (BN), Manuscritos, M/872, ZORRILLA, Francisco, Ordinarium Premostratense, 1601, fol. IIIlv.

7 Archivo Iglesia Valladolid, doc. LXXXV. Pensamos que se trata de la Dehesa de Revilla que está situada cerca de Cabezas del Villar (Ávila). La Cañada Real de Mostrencas o Montañosa, Cordel de Revilla, es una vía pecuaria que comunica la Cañada Soriana Occidental con la Leonesa Occidental,
} 
comienza a efectuar algunos contratos de arrendamiento. De esta manera en 1304, el abad de La Vid, don García, cede a Roy García en Tubilla del Lago, los molinos de Pinilla de Arcos, con la condición de que los pusiera en funcionamiento y los devolviera, finalizada la cesión de veinte años, bien reparados ${ }^{8}$. Otro ejemplo es el de Pedro Martínez de Terroa a quien el monasterio, el 5 de noviembre de 1304, arrienda la aldea de Fuentelcésped y diversas heredades en Recuerda, Quintanilla y Riobaños por un periodo de veinte años, recibiendo el abad en el momento del contrato $4.700 \mathrm{mrs}$. Lo mismo que en el caso anterior, transcurrido el tiempo establecido, las heredades habrían de ser devueltas al monasterio con todas sus mejoras y con las gentes que allí se hubieran asentado ${ }^{9}$.

En la primera mitad del siglo XIV el monasterio de La Vid ve frenar su desarrollo económico respecto a siglos anteriores; sin embargo su capacidad económica continúa siendo importante como lo demuestran las numerosas obras realizadas en la fábrica del monasterio o la cuantía de sus compras por un valor cercano a los $20.000 \mathrm{mrs}^{10}$. También se producen dos importantes donaciones que se destinan, por expreso deseo de los donantes, a la fábrica del monasterio. Por el contrario, en la segunda mitad del siglo, decrecen las compras en La Vid hasta el punto de que no hay ningún documento en este tiempo sobre adquisiciones del monasterio pero sí encontramos menciones a la pobreza del cenobio en otros dos diplomas: uno en 1355, por el que el monarca Pedro I ordena que se respeten las heredades y los derechos del monasterio en atención a su pobreza; y otro en 1375, por el que el infante Juan (futuro Juan I) toma en encomienda al monasterio por su "gran pobreza»"1. Significativamente los reyes del siglo XIV confirman reiteradas veces el privilegio de Fernando IV donde se exime al monasterio de la obligación de aposentar a ricos hombres evitando así el gran coste económico que estas estancias suponían para el convento ${ }^{12}$.

El siglo XV presenta un cambio significativo en la forma de gestión de la propiedad del monasterio que pasa a explotarse de manera indirecta. Los canónigos

desde Cabezas del Villar hasta Medina del Campo (Valladolid). En la unión con la Cañada Soriana Occidental está la Dehesa de Revilla que da nombre al cordel.

${ }^{8} 29$ junio 1304. AHN, Clero, carp. 381, n.. 13.

9 La situación de enfrentamiento civil que caracteriza el reinado de Fernando IV queda patente con la cláusula de prórroga de este contrato para el caso de que hubiere guerra: «...et si en este tienpo destos veynte annos lo que Dios non quiera guerra ouier por que uos el dicho Pero Martinez non podades labrar que uos arrengades et lo tengades adelante otro tanto tienpo quanto fuere al tienpo acabado que non podades labrar de los veynte annos...». AHN, Clero, carp. 381, n..- 14.

${ }_{10}$ AHN, Clero, carp. 382, n.ำ 1. AHN, Clero, carp. 383, n.ำ 10. AMV, Tumbo de La Vid, cod. 2, fol. 791. A cargo de todas estas operaciones económicas se encontraba el mayordomo del abad, que aparece mencionado en diversos documentos. «... e que lo auian prendado el mayordomo del abad de la Vid...». AHN, Clero, carp. 382, n. 4 .

${ }_{11}$ «[...] et el monesterio es venido a grand pobreza [...]». AHN, Clero, carp. 383, n. .17 . «[...] que yo tomo en mi guarda et en mi encomienda et en mi defendimiento al dicho abbad et conuento et al dicho monesterio et a los sus vassallos et criados et apaniaguados et a todas las sus cosas [...]”. AHN, Clero, carp. 383, n.으. 21 .

${ }_{12}$ AHN, Clero, carp. 381, n. ${ }^{-11}$. 
dejan de encargarse de sus granjas y las arriendan a largo plazo mediante censos enfitéuticos. El censo fue el contrato para la cesión de las grandes explotaciones cuando no reportaban beneficios considerables a las arcas monásticas. Estos instrumentos de arrendamiento nos permiten conocer el volumen de rentas censualistas que tenía el monasterio y la época del año en que se realizaron estos contratos e incluso, a veces, las razones de estos negocios jurídicos ${ }^{13}$. Las contrapartidas a estas concesiones eran percibidas generalmente en cereal al que se añaden, a veces, cabezas de ganado o gallinas. El transporte se soluciona exigiendo la entrega en el monasterio o en las casas que a este efecto tenían situadas los canónigos vitenses en muchos lugares. Se solía pagar a finales de verano: el día 8 (Santa María) o día el 29 de septiembre (San Miguel).

Por otra parte, en este momento se fortalecen los entes locales. Son los concejos de realengo o señorío las entidades más interesadas en la explotación agraria y quienes con más frecuencia acuden a tomar a censo las grandes explotaciones. Esta institución comunitaria incrementará su relevancia en la vida local por su papel de intermediario como arrendador de las propiedades monásticas y canalizador de las rentas reales ${ }^{14}$. En la documentación constan los numerosos pleitos que el cenobio mantuvo tanto con concejos vecinos como con particulares sobre lindes y aprovechamientos de las heredades monásticas en los siglos anteriores. Cabe pensar en la presión señorial que se pudo ejercer sobre el monasterio ya que en el siglo XV el monasterio de La Vid arrendará muchas de sus heredades a los concejos donde éstas se sitúan. Los censos enfitéuticos hicieron que con el paso del tiempo, las propiedades pasaran a manos de estos concejos determinando la ruina del monasterio.

Estas presiones locales se constatan en el caso de Hontoria cuando en 1450 el abad concede a censo perpetuo la hacienda que el monasterio posee en sus términos a ciertos vecinos particulares, por 36 fanegas de pan terciado anuales. Ello motivará la queja del concejo, muy interesado en dicho acuerdo. El concejo elevará su queja al abad retortense puesto que el monasterio de La Vid era filial de Santa María de Retuerta; Martín de Peñaranda, nuevo abad de La Vid, otorgará el censo al concejo en las mismas condiciones que tenían los vecinos, previa renuncia de éstos ${ }^{15}$.

13 RODRÍGUEZ DE DIEGO, José Luis, «Hacia una catalogación y mecanización de un importante fondo documental: los censos", en ANABAD, XXXII, 1982, n. 3, pp. 293-306.

14 OLIVA HERRER, Hipólito Rafael, «El mundo rural en la corona de Castilla en la baja Edad Media: dinámicas socioeconómicas y nuevas perspectivas de análisis», en Edad Media. Revista de Historia, 8, 2007, Universidad de Valladolid, pp. 295-328. BONACHÍA HERNANDO, Juan Antonio, «Concejo, castillo y oligarquías: poder y señorío en territorio burgalés a fines de la Edad Media», en La fortificación medieval en la Península Ibérica, Centro de Estudios del Románico, Aguilar de Campoo, 2001, pp. 71-81.

15 «Hay un traslado autorizado [...] por la qual pareze que siendo abbad de este conuento don Fernando de Aranda dio a zenso perpetuo a ciertos vecinos particulares de Ontoria toda la hacienda $y$ heredad que el conuento tenia alli, $y$ en sus terminos, por 36 fanegas de pan terciado, trigo, zeuada $y$ zenteno por iguales partes y medidas con la medida real derecha y mas seis gallinas, puesto todo en este conuento a su costa el dia de Nuestra Senora de Septiembre de cada un año, so pena del doblo. 
A lo largo del siglo XV, el monasterio otorga en censo enfitéutico en 1400 a la villa de Alcozar, la granja de Cubillas por 1.600 mrs y un yantar ${ }^{16}$; en 1410 a la villa y vecinos de Coruña del Conde, la granja y término de Brazacorta por 200 fanegas de pan terciado ${ }^{17}$; otorga, en 1448, en censo perpetuo, la granja de Santo Domingo, perteneciente a las monjas del priorato de Coro, al concejo de Fresnillo por 20 fanegas de pan terciado (trigo, cebada y centeno) y cuatro gallinas ${ }^{18}$. También da en 1449 al concejo de Gumiel de Izán la granja de Moraldiez que tenía el monasterio en término de Villanueva, aldea de Gumiel, por 2.080 mrs anuales ${ }^{19}$. Asimismo a la villa de Tobilla a censo perpetuo, en 1453, sus heredades en la villa y la granja de San Yuste en el término de Valdehande por 33 cargas de pan (de a 4 fanegas) terciado y un yantar ${ }^{20}$; en 1459 a la villa de Berlanga, las heredades del monasterio en la misma villa por 650 mrs anuales ${ }^{21}$; al concejo y hombres buenos de Fresnillo en 1460, un censo perpetuo enfitéutico sobre toda la heredad de pan llevar que dicho priorato tenía en el término de Sarcedo, debajo de su campana, en término de la villa de Aranda y en término de Fresnillo, por 70 fanegas de pan mediado y 20 galeadas de paja ${ }^{22}$. Un acuerdo entre el monasterio y don Diego de Avellaneda en 1473 permite al abad conceder al concejo de Langa y Oradero, el término de Villanueva por 1.000 mrs anuales y 12 gallinas $^{23}$. El monasterio también da a censo perpetuo al concejo y vecinos de Valdevarnes (Segovia) en 1483 las heredades que tenía allí por 16 fanegas de trigo y cebada y 5 gallinas ${ }^{24}$; y al concejo de Caleruega en 1491, las granjas de Recuerda, Santa Olalla y Quintanilla de la Puente del Camino por 160 fanegas de pan terciado, 6 gallinas y un yantar ${ }^{25}$. Firma asimismo en 1426 un contrato de censo con el concejo de Aranda de Duero sobre las granjas de Revilla de Olleros, La Paliza y Páramo por 65 florines de oro aragonés ${ }^{26}$ y otorga en censo en 1490 a los concejos de Olmedillo, Quintana y Anguix, las granjas de Arroyo y Revilla de Mío Cid por $4.500 \mathrm{mrs}^{27}$.

\footnotetext{
Y pareze que el conzejo de Hontoria y los dichos vecinos infitriotas se conuinieron entre si de transegir este zenso al conzejo, y para esto el concejo embio a sus Procuradores con su poder y con el apartamiento de dichos vecinos infitriotas al conuento y requirieron al reverendo Abbad, que a la sazon era $D$. Fr. Martin de Peñaranda, por la gracia de Dios y de Roma [...] diesen al concejo el dicho zenso protestando el daño que se seguia al conuento en hauerle dado a vecinos particulares en que no tenia seguridad, la que tenia en dicho concejo [...]" AMV, Tumbo de La Vid, cod. 2, fol. 557. 20 de diciembre de 1450.

${ }^{16}$ AMV. Tumbo de La Vid, cod. 2, fol. 84.

${ }_{17}$ AHN, Clero, carp. 384, n. -18.

${ }^{18}$ El priorato de Coro de Fresnillo (de las Dueñas) había sido una filial femenina del monasterio de La Vid; en el siglo XV pertenecía al cenobio vitense. AHN, Clero, carp. 385, n.․․ 5 .

${ }_{19}$ AMV, Tumbo de La Vid, cod. 2, fols. 542-543.

${ }^{20}$ AMV, Tumbo de La Vid, cod.2, fols. 729-730.

${ }^{21}$ AMV, Tumbo de La Vid, cod. 2, fols. 186-187.

${ }^{22}$ AMV, Tumbo de La Vid, cod. 2, fols. 333-334.

${ }^{23}$ AMV, Tumbo de La Vid, cod. 2, fol. 637.

${ }^{24}$ AMV, Tumbo de La Vid, cod. 2, fol. 875.

${ }^{25}$ AMV, Tumbo de La Vid, cod.2, fols. 557-559.

${ }^{26}$ AMV, Tumbo de La Vid, cod.2, fol. 97. Este censo debió frustrarse porque en 1429 el abad de La Vid se dirige al Papa Martin V (1417-1431) pidiéndole que eximiera al monasterio del pago de 65 florines aragoneses anuales que le reclamaba el concejo de Aranda de Duero por las granjas de Revilladelos (Revilla de Olleros), La Paliza y Los Páramos. Archivo Vaticano. Reg. Supp. 237, fol. 41r.

${ }^{27}$ AMV, Tumbo de La Vid, cod. 2, fol. 919.
} 
En otras ocasiones el monasterio establece contratos de censo con particulares que, debido a la magnitud de la propiedad, debían ser poderosos y solventes. En este sentido es relevante lo indicado por Esther Pascua sobre la existencia de modelos de "gestión mixta» que facilitarían la entrada de la institución monástica en la comunidad y/o villa estableciendo vínculos con personas de cierta preeminencia social, y la posterior explotación directa ${ }^{28}$. De los diversos otorgamientos de cartas de censo perpetuos a particulares, desconocemos el origen social de la mayoría ${ }^{29}$. Pero en el censo enfitéutico que el monasterio de La Vid establece sobre las heredades que tenía en Alcoba de la Torre con Gutierre Delgadillo, se hace mención a su condición de «vasallo del rey» ${ }^{30}$.

Además de censos, el monasterio venderá diversas heredades a particulares a cambio de juros situados en diferentes rentas. Se vislumbra el interés del convento por disponer de rentas fijas y continuadas en el tiempo. En 9 de octubre de 1422 fray Juan de Moradillo, abad de La Vid y el convento dan a Juan Delgadillo, guarda del rey, el lugar de Cevico Navero, vasallos, tierras y todo lo demás que en dicho lugar les perteneciere por $5.000 \mathrm{mrs}$ de juro perpetuo y allá donde el convento quisiese situar. El monasterio había analizado esta heredad que sólo rentaba $600 \mathrm{mrs}$ en dinero y 5 cargas de pan mediado (trigo y cebada) que equivalían a $900 \mathrm{mrs}$, lo que suponía $1.500 \mathrm{mrs}$ anuales, mucho menos de lo que el comprador ofrecía ${ }^{31}$. En 3 de febrero de 1437, en Torrecilla (cerca de Torrelaguna) el abad de La Vid y el convento, venden a Alfonso Pérez del Venero, contador mayor de Juan II, la granja de Torre del Conde con el Almaján, que estaba despoblado ${ }^{32}$. Bajo la forma de trueque y por mandato del rey, en 4 de enero de 1463, el monasterio y su abad, don Sancho de Aranda, acuerdan un censo enfitéutico con los concejos de Olmedillo y Quintana representados por don Luis Vaca, guarda del rey, por el que el monasterio da a los concejos las granjas de Arroyo y Revilla de Mío Cid con todas sus pertenencias y derechos perpetuamente ${ }^{33}$.

28 «La hipótesis que se baraja es que en el feudalismo las instituciones extracomunitarias tenían muchas dificultades para organizar procesos de producción al margen de las villas y aldeas. Para movilizar la fuerza de trabajo necesitaban «intermediarios comunitarios». Esto implicaba no sólo un escalón añadido de extracción de renta, sino una acción económica por parte de los centros eclesiásticos dirigida a crear una malla de relaciones sociales que permitiera la conexión». PASCUA ECHEGARAY, Esther, «Los contextos sociales e institucionales de una economía monástica: Santa María de Montederramo en el siglo XIII», en Revista de Historia Económica, Año XVII, Invierno 1999, n. 1, pp. 51-88.

29 Diego Fernández y otros vecinos del monasterio sobre la granja de Guma y la casa de don Alonso. AHN, Clero, carp. 384, n. ⒗ Martín Ferrández, vecino de Fuentelcésped, sobre las casas en que moraba AHN, Clero, carp. 384, n.ํ 17. Juan Martínez, vecino de Roa, sobre unas casas en la calle de San Juan de este lugar AHN, Clero, carp. 385, n.ำ 1. Luis Fernández de la Fuente, vecino de Valbuena, sobre las heredades que al monasterio pertenecían en Camarma del Caño, Camarma de Esteruelas, Camarma de los Frailes, Buges y en sus diversas tierras y términos. AHN, Clero, carp. 385, n.ำ 7 .

30 AMV, Tumbo de La Vid, cod. 2, fol. 126.

${ }^{31}$ AMV, Tumbo de La Vid, cod. 2, fol. 913.

${ }^{32}$ AMV, Tumbo de La Vid, cod. 2, fol. 597.

${ }^{33}$ AHN, Clero, carp. 385, n. 18. 
Si el pago de los censos se efectuó según lo estipulado en los diferentes contratos analizados - no nos constan pleitos promovidos por el monasterio reclamando sus derechos-, el cenobio de La Vid debía recibir anualmente a finales del siglo XV, 69 florines de oro aragonés y $5.330 \mathrm{mrs}$; tres yantares, 20 galeradas de paja y 33 gallinas; 93 fanegas de pan, 247 fanegas de pan mediado (trigo y cebada) y 871 fanegas de pan terciado (trigo, cebada y centeno). Además, tenía 10.000 mrs situados en Tordelaguna o Torrelaguna (5.000 mrs en las carnicerías y otros 5.000 en las alcabalas del vino blanco) y 4.500 mrs situados en las de los paños blancos y bruneles de Palencia.

El estudio de la evolución de las rentas del monasterio de La Vid se ve dificultado por la inexistencia de libros de cuentas por lo que el acercamiento a la realidad económica del cenobio ha de hacerse a través de la documentación conservada $^{34}$. A partir de esos datos es posible realizar un acercamiento a la evolución económica del monasterio a través del siguiente gráfico:

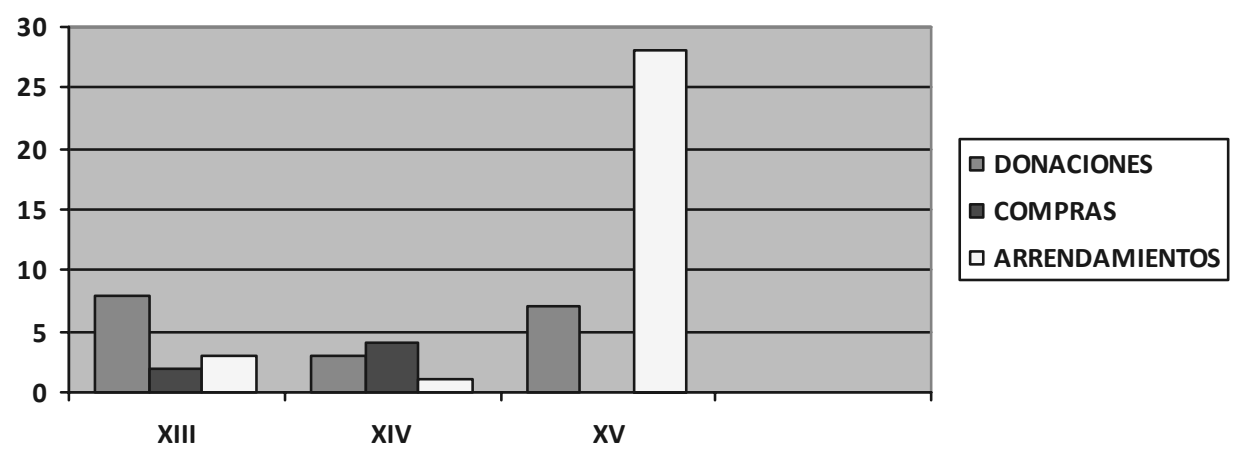

Evolución Económica del Monasterio de La Vid

\section{LAS RAZONES DEL CAMBIO DE LA FORMA DE EXPLOTACIÓN DEL DOMINIO MONÁSTICO VITENSE}

Durante el siglo XIV se desarrollan dos tipos de contratos agrarios o instrumentos jurídicos que regulan la relación sobre la tierra: los arrendamientos y los censos. Los censos enfitéuticos van a permitir el acceso a la propiedad de pequeños campesinos desde la gran propiedad. Como señala Mercedes Borrero, los parámetros que explican la aparición de sistemas de explotación concretos son la estructura de la propiedad de la tierra, los niveles demográficos y la mentalidad económica de los grandes

${ }^{34}$ Conocemos los riesgos que esto supone pero situar cronológicamente las distintas posesiones según la datación de los documentos en los que aparecen por primera vez es el medio utilizado habitualmente para describir la evolución diacrónica de la formación del patrimonio monástico. 
propietarios $^{35}$. El monasterio sin embargo cambiará el sistema de explotación de la tierra en el contexto de la crisis del siglo XIV cuyo estudio se ha centrado en dos aspectos; en primer lugar en la despoblación ocasionada por la Peste y sus consecuencias demográficas y geográficas; y en segundo lugar, en las crisis agrarias. A esto se añaden circunstancias políticas como la paralización de la Reconquista, la guerra de sucesión de Sancho IV, las minorías de Fernando IV y de Alfonso XI, la guerra fratricida entre Pedro I y Enrique de Trastámara y los enfrentamientos entre la nobleza. Todos estos elementos se materializarán en la llamada depresión del siglo XIV y su consecuente recesión económica y demográfica ${ }^{36}$.

Sobre la Peste Negra no aparecen menciones directas en la documentación vitense, pero sí se aprecia el interés monástico por incrementar la población en sus dominios; en un arrendamiento efectuado en 1304 se estipula que una vez finalizado el mismo, se devolviese el término «con los vasallos que la hubiesen poblado ' ${ }^{37}$; en un documento de 1348, una concordia con Peñaranda sobre términos, se estipulaban alicientes para favorecer el establecimiento de pobladores ya que si el monasterio arrendase casas que no estuvieran pobladas, los arrendatarios tendrían ciertas ventajas: se les permitiría que sus ganados pastasen y que ellos sembrasen y cosechasen en esos términos ${ }^{38}$. Estos datos indican las dificultades con las que se encontraba el monasterio por la escasez de mano de obra en el contexto de la crisis demográfica, y la necesidad de retener al campesinado para las labores agrícolas en sus granjas, a las que se unía el descenso, que parece generalizado, de conversos en los monasterios bajomedievales ${ }^{39}$.

En cuanto a las crisis agrarias, algunos de los factores que las explican son: la falta de mano de obra, las dificultades económicas para la inversión y la necesidad de elevar las rentas de las propiedades por parte de los grandes propietarios; en este caso, el monasterio de La Vid. A ello habría que añadir la climatología adversa del siglo XIV, la posible sobreexplotación agraria y el generalizado clima de inseguridad $^{40}$. La incertidumbre de las cosechas debido a todos estos condicionantes induciría a los canónigos vitenses a buscar la seguridad de las rentas fijas frente a hipotéticos ingresos.

Otro condicionante fue el recurso a la violencia por parte de la nobleza como forma de superar las dificultades con que tropezaba la reproducción de sistema

${ }^{35}$ BORRERO FERNÁNDEZ, Mercedes, «Sistemas de explotación de la tierra en la Andalucía occidental durante el siglo XIV», En la España Medieval, 1989, 12, pp. 131-161.

${ }^{36}$ MARTÍNEZ GARCÍA, Luis, El Hospital del Rey de Burgos. Poder y beneficencia en el Camino de Santiago, Universidad de Burgos, Burgos, 2002, p. 140.

37 AHN, Clero, carp. 381, n. 14.

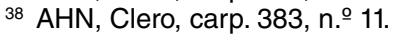

39 CABRILLANA, Nicolás, «Los despoblados en Castilla la Vieja» en Hispania, n. 119, 1971, pp. 458-

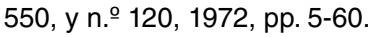

40 «Todos los testimonios castellanos de la primera mitad del siglo XIV hablan de malas cosechas y de hielos. Hacia 1325 hubo una gran hambruna. Y las Cortes de Burgos de 1345 se quejan de «una simiente muy tardía, por muy fuerte temporal e grandes nieves e yelos». José Luis COMELLAS, Historia de los cambios climáticos, Rialp, Madrid, 2011, p. 184. 
feudal; violencia que parece se hizo general desde los años 70 de siglo XIII hasta finales del siglo XIV. Julio Valdeón estima que las caídas de las rentas señoriales obedecían a una combinación de múltiples factores como la regresión demográfica, el retroceso del espacio cultivado y el desajuste entre la elevación general de los precios de los productos manufacturados y el carácter fijo de numerosos tributos derivados de la jurisdicción señorial ${ }^{41}$. En La Vid constan los intentos de elementos de la nobleza por hacerse con los bienes del monasterio, como prueban la actuación de Ramir Flores de Guzmán respecto a Fuentelcésped y de Ramir Gutiérrez respecto a la villa de Berlanga. Otro ejemplo de abusos señoriales nos llega indirectamente a través de la venta que el abad y el convento hacen de la heredad de Cevico Navero en 1422; señala el Tumbo del monasterio que los vasallos del lugar sufrían "agravios y muchas exenciones injustas que les hacian muchos señores» ${ }^{42}$.

El cambio de la forma de explotación económica del dominio del monasterio de La Vid se realiza a partir de 1400, año del primer censo enfitéutico. Los canónigos vitenses pasan de administrar de manera directa las granjas que poseían a cederlas para su explotación indirecta mediante censos enfitéuticos, principalmente a los concejos en donde estas granjas estaban situadas pero también a diversos particulares ${ }^{43}$.

Estos abusos parece que también se realizaban por parte de vecinos de los lugares de La Vid. Así en 16 de mayo de 1448, debido a lo poco que rentaba y a los conflictos con los vecinos de Fresnillo, que entraban en sus términos, el abad de La Vid don Fernando y el prior de Fresnillo, fray Juan de Moradillo, decidieron vender la granja de Santo Domingo perteneciente a este priorato desde su fundación ${ }^{44}$. Otra razón que esgrime el Tumbo de La Vid al mencionar un censo es «que esta posesión era poco útil al monasterio porque estaba casi todo perdido y los vecinos del lugar no lo querían arrendar ${ }^{45}$. Igualmente, en la venta de la granja de Torre del Conde, en 1437, se hace notar que el lugar estaba despoblado.

El dominio del monasterio quedaba más asegurado frente a las intromisiones de los caballeros si el enfiteuta era un concejo ya que, de esta manera, se institucionalizaba la posesión de los bienes objeto del censo y por otra parte, el monasterio creaba una red clientelar con la sociedad rural de su entorno. Además, el debilitamiento de la demanda de tierra a raíz de la disminución de la población rural limitaría el número de posibles arrendatarios particulares.

41 VALDEÓN BARUQUE, Julio, «La crisis del siglo XIV en la Corona de Castilla», en Homenaje a

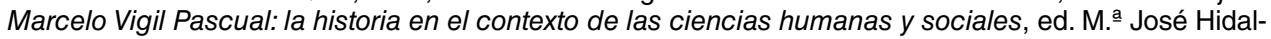
go de la Vega, 1989, pp. 217-236.

42 AMV, Tumbo de La Vid, cod. 2, fol. 913.

${ }^{43}$ Esta segunda opción no debió ser bien aceptada por los concejos como hemos visto en el caso de Hontoria de Valdearados.

44 AHN, Clero, carp. 385, n. $\div 5$.

45 AMV, Tumbo de La Vid, cod. 2, fol. 126. 
Otro motivo que induciría a los canónigos a cambiar el modo de explotación de sus dominios vendría determinado por la lejanía de los mismos al cenobio. Algunos documentos nos proporcionan razones de este cambio señalando que resultaba muy costoso enviar canónigos a gestionar las granjas y que algunas estaban situadas lejos del monasterio lo que dificultaba el control de la explotación y favorecía el abuso ${ }^{46}$.

Conocemos también de los abusos que las malas encomiendas ejercieron sobre el cenobio vitense. En 1316 el monasterio arrendó a Diego Ordoñez de Tarroa la aldea de Fuentelcésped durante un periodo de veinte años por $4.000 \mathrm{mrs}{ }^{47}$. Este arrendamiento provocó un largo y gravoso pleito para el monasterio que consiguió al fin recuperar la aldea. Se entiende que el abad, don Juan, estuviese "escarmentado de las encomiendas" como señala el Tumbo ${ }^{48}$ y que decidiese, con el convento, arrendar en abril de 1347 la aldea de Fuentelcésped a veinte vecinos del lugar ${ }^{49}$. Ya en 1380, por petición del abad de La Vid, Juan I había ordenado a Juan González de Avellaneda y a Lope de Ochoa, su hermano, que dejasen la encomienda que sin derecho tenían sobre Fuentelcésped y Tubilla del Lago, respectivamente. Ambos hacían sus tributarios a los vasallos del monasterio. En el documento el monarca carga contra las malas encomiendas que producían pobreza en iglesias y monasterios ${ }^{50}$.

Otra razón que llevaría al monasterio a dejar de explotar directamente las granjas vendría dada por el llamado factor mercado ${ }^{51}$, al considerar que las alteraciones de los precios serían consecuencia de los mecanismos de comercialización y no sólo de los vaivenes de la producción agraria ${ }^{52}$. En este sentido un elemento a tener en cuenta sería la necesidad del crédito en las comunidades rurales y en el monasterio. Dentro del acuerdo que puso fin al pleito entre el monasterio y Ramir Flores de Guzmán en 1347, varios judíos vecinos de Aranda recibieron diversas cantidades de dinero por cartas de deudas que tenían sobre el concejo y

46 En 1478 el monasterio de Santa María de Bujedo entregó al concejo de Montuenga la granja de Cogolillos «porque es cosa que bien viene al dicho monasterio e convento asi por ser renta muy çierta la que asi nos dan por ella, e muy sana e segura, e de mayor renta que fasta aqui avemos avido e nos aya rendido e podria rendir, e porque la dicha granja es apartada de dicho monasterio...". AHN, Clero. Carp. 172, n.ำ 13.

47 AHN, Clero, carp. 381, n. ${ }^{-17}$.

48 El monasterio acababa de terminar un largo pleito con Diego Ordóñez y su mujer, a los que había dado en encomienda la aldea de Fuentelcésped. AMV, Tumbo de La Vid, cod. 2, fol. 505.

49 AHN, Clero, carp. 383, n.ำ.

50 AHN, Clero, carp. 384, n.ำ2.

51 Aunque la historiografía sobre la crisis rural del siglo XIV vio en un primer momento la Peste Negra como causa principal de la crisis, las nuevas tendencias se centran en el estudio del factor mercado para explicar los cambios en la producción agraria, y en los estudios regionales. Pese a todo, el estudio del mundo rural del XIV sigue presentando grandes lagunas. BORRERO FERNÁNDEZ, Mercedes, «El mundo rural y la crisis del siglo XIV. Un tema historiográfico en proceso de revisión», en EDAD MEDIA, Revista de Historia, 8, 2007, pp. 37-58.

52 La conjoncture de 1300 en Méditarrenée occidentale. Monnaie, crédit et fiscalité dans le monde rural, Madrid, Casa de Velázquez, 8-10 febrero 2007. 
vecinos del lugar de Fuentelcésped ${ }^{53}$. Otro testimonio de crédito lo encontramos en una compra que el abad Juan y el convento de La Vid realizan en 1347 al concejo de Tobilla, que vende estas tierras al monasterio para redimir las deudas contraídas con prestamistas judíos; tal condición se manifiesta expresamente en el documento ${ }^{54}$. En otros casos es el mismo monasterio el que concede préstamos a particulares; así en 1347 presta 1.000 mrs a unos vecinos para la compra de bueyes ${ }^{55}$ y $650 \mathrm{mrs}$ al concejo de Tubilla para el pago de una obligación que tenían con Ramir Flores de Guzmán ${ }^{56}$.

La gestión indirecta de los bienes del monasterio puede ser interpretada como una fórmula de ahorro por parte de los monasterios; la cesión de bienes para su explotación podría analizarse en clave de ventaja para el señor, sobre todo en momentos de subida de salarios y oscilación de precios consiguiendo afianzar un ingreso permanente sin asumir los costes de mano de obra y mantenimiento. Por otro lado los monasterios, tal y como señala Salustiano Moreta, tuvieron que hacer frente a importantes gastos de mantenimiento de sus edificios e instalaciones lo que se evitaría con la gestión indirecta ${ }^{57}$. Esto también lo hemos visto durante el siglo XIV en el monasterio de La Vid a través de sus reparaciones y obras en el monasterio y en sus granjas.

Tampoco podemos descartar como motivo de los censos enfitéuticos del monasterio la mala gestión llevada a cabo por los canónigos encargados de las granjas. En este sentido recordamos el caso puntual del monasterio premostratense de San Cristóbal de Ibeas, que tenía la granja o priorato de San Miguel de Villapedro, dirigida en el siglo XV por un profeso de Ibeas, fray Juan de Miranda, quien tras una inspección del abad de La Vid y de otro visitador de la Orden y por su mandato, fue llevado a prisión a causa de su vida disoluta; huyó y cedió su priorato al monasterio jerónimo de Fresdelval, que en 1461 se valdrá de ello para disputar este priorato al cenobio de Ibeas mediante un pleito ${ }^{58}$.

\footnotetext{
${ }^{53}$ Así, don Abrahan Cavaña recibió 700 mrs; doña Orosol, mujer que fue de Rabí Mayr, 750 mrs; Yñegada, mujer que fue de don Cag, 750 mrs.; Mosse Mañe, 110 mrs. y Huda, hijo de Mayr de Aza, 110 mrs. AMV, Tumbo de la Vid, cod. 2, fol. 46.

${ }^{54}$ AHN, Clero, carp. 383, n. .10.

${ }_{55}$ AHN, Clero, carp. 383, n. 9. «... mill marauedis desta moneda que agora corre que fasen dies dineros el marauedi para que compredes bueyes..».

${ }^{56}$ AMV, Tumbo de La Vid, cod.2, fol. 791.

57 MORETA VELAYOS, Salustiano, Rentas monásticas en Castilla: problemas de método, Salamanca, 1974.

${ }_{58}$ El capiscol de la catedral de Burgos y juez apostólico, Luis González de Llanos, dictó sentencia por la que el prior y convento de Fresdelval renunciaron a favor del de lbeas, quedándose con los frutos obtenidos durante el proceso, excepto los ornamentos, cálices y campanas que tuvieron que devolver al priorato. LÓPEZ DE GUEREÑO, M. ${ }^{a}$ Teresa, Monasterios medievales premostratenses. Reinos de Castilla y León, Junta de Castilla y León, Salamanca, 1997, pp. 294-295. Otro dato sobre la mala gestión nos lo proporciona la granja de Torrecilla, situada en el término de la villa de Tordelaguna. Esta granja estuvo dirigida por un religioso pero hacia 1555 «se perdió casi toda la hacienda por el mal trabajo de los mayordomos seglares que ponia el monasterio", razón por la que el monasterio decidió enviar de nuevo a un religioso para que se encargase de dirigirla. Esta decisión no resultó rentable «por ser mucho el gasto y poco provecho" lo que motivó su venta en 1574. AMV, Tumbo de La Vid, cod. 2, fol. 767.
} 


\section{EL MODO DE EXPLOTACIÓN ECONÓMICA EN EL CONTEXTO DE LOS MONASTERIOS CASTELLANOS Y LEONESES}

Aplicando algunos elementos de la metodología de la historia comparada, hemos tratado de analizar la evolución de los modos de explotación de algunos monasterios de distintas órdenes monásticas y conventuales durante los siglos XIV y $\mathrm{XV}$ en el ámbito geográfico castellano y leonés.

\section{La Orden Benedictina}

El sistema de explotación de la tierra utilizado por los monasterios benedictinos consistía en prioratos dirigidos por un prior que tenían una gran autonomía y que utilizaba mano de obra sierva o campesinos sometidos a prestaciones.

En el monasterio benedictino de San Zoilo de Carrión de los Condes (Palencia), la explotación directa se mantiene hasta entrado el siglo XIII (comienzan a aparecer los censos a partir de 1378) y en adelante se reduce hasta concluir a partir del XIV a sólo lo necesario, lo que la comunidad estimaba adecuado para su propio sustento y una eventual intervención en el mercado ${ }^{59}$.

Asimismo en otro cenobio benedictino, el de San Salvador de Oña (Burgos), desde el siglo XIII se detecta el retroceso de la explotación directa del dominio por los monjes que fueron limitándose a administrar rentas, en especie y en dinero, durante el siglo XIV ${ }^{60}$. Y en el siglo XV se procede a la sustitución de la explotación directa por rentas fijas para evitar el abandono de las explotaciones y mejorar la gestión del patrimonio, como recoge un testimonio del Libro de Cuenta de 1494: «[...] Labra el monesterio e sus grangias a propias espensas mill e dozientas e quarenta e quatro obreros de parrales e treçientos e sesenta e un obreros de vinnas, en que se cogieron el dicho anno pasado de vino limpio ocho mill e treçientas e treynta e çinco cántaras, de las cuales, descontando que costaron labrar los dichos parrales el vinnas a çiento e treynta mrs. el obrero de parral y el de la vinna a dos reales e medio con el vendimiar e acarrear e hazer el vino e encubarlo, çiento e noventa mill e quatroçientos e çincuenta y siete mrs. E las dichas ocho mill e treçientas e treynta y çinco cántaras de vino podrían valer contando a veynte e çinco mrs. la cántara, dozientas e ocho mill e treçientos e seten-

59 PÉREZ CELADA, Julio A., El monasterio de san Zoilo de Carrión. Formación, estructura y decurso histórico de un señorío castellano-leonés (siglos XI al XVI). Universidad de Burgos, 1997. PALACIO SÁNCHEZ, M. a Luisa, San Zoil de Carrión (siglos XI-XIV), Palencia, Diputación de Palencia, 1990. GARCÍA GONZÁLEZ, Juan José Vida económica de los monasterios benedictinos en el siglo XIV, Valladolid, 1972.

60 SUÁREZ BILBAO, Fernando, y VIÑUALES FERREIRO, Gonzalo, «El monasterio de San Salvador de Oña en la baja Edad Media», en Circunstancia. Revista de ciencias sociales del Instituto Universitario de Investigación Ortega y Gasset, n.ำ24, 2011. DIAGO HERNANDO, Máximo, «Fuentes de ingresos y situación económica del monasterio de Oña en los siglos XV y XVI» en Anuario de Estudios Medievales, 28, (1998), pp. 451-486. 
ta e çinco mrs. de los quales sacando los dichos çiento e noventa e quatroçientos e çincuenta e siete mrs. de la dicha costa quedan diez e siete mill e noveçientos diez e ocho $m r s .[\ldots] \gg 61$.

\section{La Orden Cisterciense}

Frente al sistema benedictino, el Císter rechaza el uso de mano de obra servil, organizando sus explotaciones agrícolas mediante granjas ${ }^{62}$. La explotación directa de la tierra exigía el concurso de numerosos conversos e incluso la ayuda de los propios monjes en determinadas tareas, por lo que la carencia de vocaciones hizo clausurar la gestión directa de algunas granjas en la segunda mitad del XIII ${ }^{63}$ Por otra parte, el deterioro de las condiciones de paz y seguridad acabaría por desarticular los dominios y desde el siglo XIV, las granjas explotadas de forma directa que habían sido abandonadas, pasan a ser cedidas mediante arrendamientos o foros. En el siglo siguiente, en los contratos no se establecen ya condiciones de conservación y mantenimiento, síntoma de que al monasterio solo le interesaba ya la renta que pudiera percibir ${ }^{64}$.

El cambio de forma de explotación se observa así en el monasterio cisterciense de San Miguel de las Dueñas (Palencia) que utiliza el modo de explotación directa en el espacio del coto monástico mediante las prestaciones de los vasallos adscritos al cenobio y el sistema de explotación indirecta en el resto de su dominio. La enfiteusis es el más importante de los sistemas de explotación indirecta utilizados por el monasterio y el único documentado, ya que de los 27 documentos registrados entre 1290 y 1490, 14 son contratos de foro, con total ausencia de los contratos de arrendamiento ${ }^{65}$.

También en el monasterio de Santa María de Moreruela (Zamora), desde mediados del siglo XIII se produce una transformación en la organización tradicional del dominio monástico en favor de la gestión indirecta, mediante arrendamientos y

61 AHN, Clero, Legajo 1.290. VIÑUALES FERREIRO, Gonzalo, «Economía del dominio monástico de San Salvador de Oña en la baja Edad Media», en San Salvador de Oña: mil años de Historia, Coord. Rafael Sánchez Domingo, Fundación Milenario San Salvador de Oña, Oña, 2011, pp. 396-407, nota 14.

62 LEKAL, Louis J., Los cistercienses. Ideales y realidad, Barcelona, 1987. PORTELA SILVA, Ermelindo La colonización cisterciense de Galicia (1142-1250), Universidad de Santiago de Compostela, Santiago de Compostela, 1981.

63 Los cistercienses del Real Monasterio de Santa María de Poblet intentarán durante el siglo XIII cambiar las bases económicas del monasterio sustituyendo la explotación directa de las tierras, amenazada por la escasez de conversos, por la posesión de dominios señoriales que no exigían mano de obra lo que llevaría a un colapso económico a finales del siglo del que parecen repuestos a principios del XIV. ALTISENT, Agustín, Les granges de Poblet al segle XV: assaig d'història agrària d'unes granges cistercenques catalanes, Institut d’Estudis Catalans, Barcelona, 1972, p. 131.

64 PÉREZ-EMBID WAMBA, Javier, El Císter en Castilla y León. Monacato y dominios rurales (siglos XII-XV). Junta de Castilla y León, Salamanca, 1986.

65 CAVERO DOMÍNGUEZ, Gregoria, y GONZÁLEZ GARCÍA, Miguel Ángel, El monasterio cisterciense de San Miguel de las Dueñas, Universidad de León, León, 2000. 
concesiones prestimoniales de las tierras, antes cultivadas directamente, que se relaciona a su vez con la disminución del número de conversos ${ }^{66}$. El principio de la crisis económica en Moreruela se produce entre 1298 y 1325. A partir de entonces el monasterio pasó de una situación de expansión a otra de recesión ${ }^{67}$.

Los orígenes benedictinos de Santa María de Carracedo (León) le llevaron a conjugar los dos sistemas de explotación seguidos por benedictinos y cistercienses respectivamente: el directo con conversos y el indirecto con campesinos dependientes; uno aplicado en la reserva señorial y el otro en los mansos, los dos componentes clásicos del señorío territorial. A partir de mediados del siglo XIII, la situación de las granjas cambió debido a la reducción el número de conversos y a partir de 1260, los conversos desaparecen de la documentación de Carracedo. El monasterio entregó las granjas en préstamo o cedió la tierra bajo diversas formas de enfiteusis. Posteriormente, en los siglos XIV y XV, se generalizó su cesión mediante contratos de foro de larga duración ${ }^{68}$. A partir de entonces sólo permanecieron en explotación directa las tierras cercanas al monasterio, trabajadas por criados $^{69}$.

\section{Orden de San Agustín: Monjes Premostratenses y Canónigos Regulares}

En el monasterio premostratense de Santa María de Aguilar de Campoo (Palencia), la primera cesión en renta se documenta en 1334 y corresponde a la granja de San Agustín de Herrera, siendo sus beneficiarios unos particulares. A través del tiempo, el censo enfitéutico se convirtió en el sistema de contratación en la administración del monasterio. A mediados del siglo XV pasará por dificultades económicas por la disminución de la producción o el abandono de las tierras por los labradores, como indican las cláusulas contractuales que obligaban a mantener pobladas las tierras arrendadas. $Y$ se generalizan los contratos de arrendamiento vitalicios por la necesidad de asegurarse largos períodos de rentabilidad

\footnotetext{
${ }^{66}$ ALFONSO ANTÓN, Isabel, La colonización cisterciense en la Meseta del Duero. El ejemplo de Moreruela, siglos XII-XIV, Zamora, Diputación de Zamora, 1986.

67 La administración de los bienes se volvió problemática por la presión que ejercían «algunos caballeros comarcanos»... Por esta razón venden en 1431 unos lugares por 15.000 mrs en un juro sobre las alcabalas del vino de Zamora al segundo conde de Benavente, quien a su vez los traspasó en 1434 al concejo de Benavente por la misma cantidad. CASQUERO FERNÁNDEZ, José Andrés, «EI monasterio de Santa María de Moreruela en la época moderna», en Moreruela, un monasterio en la historia del Císter, Hortensia Larrén Izquierdo (coord.), Junta de Castilla y León, Salamanca, 2008, pp. 144-163.

68 En 1360 el monasterio de Carracedo cedió a renta vitalicia a Juan Pérez sus heredades en La Valgoma y Cortigueira porque «estaban enallenadas en tal manera que nos nin las podiamos aver nin coller renta nin los fructos e esquilmos delas. E por esta rason, por saber nos quales e quantas eran las heredades e terras de pan, e las viñas e foros que pertenecian a los dichos monjes, e por ser certos dello...». Instituto Jerónimo Zurita, CSIC, Cartulario de Carracedo, f. 291v. Ex PÉREZ-EMBID WAMBA, Javier, El Císter en Castilla y León. Monacato y dominios rurales (siglos XII-XV). Junta de Castilla y León, Salamanca, 1986, p. 421.

69 BALBOA DE PAZ, José Antonio, El monasterio de Carracedo, Instituto Leonés de Cultura, Diputación de León, León, 2005.
} 
de las tierras y también por la incapacidad del monasterio de encarar las obras de mantenimiento ${ }^{70}$.

El núcleo principal del dominio del monasterio de Santa María de Burgohondo (Ávila), de clérigos regulares, se crea entre las últimas décadas del siglo XII y mediados del $\mathrm{XIV}^{71}$. Con posterioridad se producen pocas incorporaciones al dominio monástico, retratado en apeos y deslindes en el siglo XV. A mediados de este siglo, entre 1441 y 1557 , se organizan las propiedades para obtener un mayor rendimiento, entregando muchas de ellas mediante contratos de censo a particulares ${ }^{72}$.

La abadía de Santa María de Husillos (Palencia), empezó a perder heredades y a despoblarse sus términos durante el siglo XIV ${ }^{73}$. Así la explotación directa quedó reducida en la baja Edad Media a las tierras de cereal del coto monástico a través de trabajadores domésticos, asalariados temporales y sernas. La explotación indirecta se aplicaría a la mayor parte del dominio, en tierras distantes del monasterio, pese a ser escasos los contratos de censo hasta el siglo XVI. Los primeros censos y arrendamientos aparecen a mediados del siglo XIII pero es en siglo XVI cuando se utilizan de manera generalizada por los canónigos, reflejándose en la relación de rentas de $1555^{74}$.

El monasterio de Santa María de Trianos (León), refundado a finales del siglo XII por el magnate Tello Pérez, adscrito a la regla de San Agustín y situado muy cerca al monasterio de Sahagún, no sufrió la crisis que otros monasterios presentan desde finales del siglo XIII. Durante el XIV incluso acrecentó su patrimonio mediante donaciones, ventas y permutas, pese a sufrir usurpaciones por parte de laicos; los problemas económicos surgirán a finales del siglo $\mathrm{XV}$, cuando el monasterio se encontrará sometido a situaciones extremadamente tensas debido a la violencia ejercida por eclesiásticos y seglares contra el convento ${ }^{75}$.

Constatamos que también se procede a la cesión de los bienes mediante contratos enfitéuticos en el siglo XIV en dos cabildos catedrales, los de Segovia

\footnotetext{
70 GONZÁLEZ DE FAUVE, M. a Estela, La Orden Premostratense en España. El monasterio de Santa María de Aguilar de Campoo (Siglos XI-XV), Centro de Estudios del Románico, Palencia, 1992.

${ }^{71}$ CALVO GÓMEZ, José Antonio, Clérigos regulares en Ávila. El monasterio de Santa María de Burgohondo (Siglos XII-XV), Salamanca, 2008.

72 Ver Cuadro de los censos de la Abadía (1422-1541). Anexo 8. CALVO GÓMEZ, José Antonio, op. cit., pp. 1365-1368.

73 David MARCOS DíEZ, La Abadía de Santa María de Husillos: estudio y colección documental (904-1608), Universidad de Valladolid, 2009. Tesis doctoral. http://uvadoc.uva.es/handle/10324/857.

${ }^{74}$ Inventario de propiedades de la fábrica, mesa abacial, hospital y mesa capitular de santa María de Husillos, mandado realizar por Gutierre de Carvajal, obispo de Plasencia y tío de Francisco de Carvajal, abad de santa María de Husillos. El motivo fue el grave estado de deterioro y pérdida en que se encontraba el dominio y la documentación de Santa María de Husillos que lo justificaba. 1555, enero,1. Husillos - 1555, enero,18. Husillos. Archivo Parroquial de Ampudia (APA), Libro de los Privilegios de Husillos (LPH), ff. 214r-214v. MARCOS DíEZ, David, op. cit., doc. n.o 298.

${ }^{75}$ ROYER DE CARDINAL, Susana, «El monasterio leonés de Santa María de Trianos y su articulación con otras instancias eclesiásticas (s. XII-XV), en Hispania Sacra, LIX, 119, enero-junio 2007, pp. 7-33.
} 
y Toledo. Así ocurre en el cabildo de la catedral segoviana, cuyas heredades estaban en mano de colonos que explotaban la tierra, lo que suponía para el cabildo una fuente de ingresos mediante la renta. El abandono de los solares por parte de estos colonos dependientes originaría problemas económicos al cabildo que se vio obligado a entregar la tierra a terceros mediante contratos de larga duración ${ }^{76}$. En el caso de la catedral toledana, las circunstancias de la crisis y la disminución de sus ingresos hicieron que dejara de interesarle la propiedad efectiva de su patrimonio, preocupándose por asegurarse la percepción de ingresos fijos en dinero. Durante la segunda mitad del siglo XIV no parece que se practicase la explotación directa ya que todos los bienes que componían su patrimonio estuvieron arrendados ${ }^{77}$.

\section{La Orden de Santa Clara y la Orden de San Jerónimo}

A finales de la Edad Media, las órdenes mendicantes adoptan también este tipo de organización económica indirecta ${ }^{78}$.

El monasterio de Santa Clara de Alcocer (Guadalajara), atraviesa una época de dificultades durante el siglo XIV cuyas consecuencias fueron los endeudamientos del monasterio para cubrir sus necesidades básicas ${ }^{79}$. Durante la mayor parte del siglo XV el monasterio se mantiene en una situación de estabilidad económica, caracterizada por la realización de censos enfitéuticos sobre bienes del patrimonio inmueble del monasterio. Así, la política de arrendamientos a largo plazo y la entrega en censo de importantes bienes del patrimonio monástico a cambio de

76 GARCÍA SANZ, Ángel, «Cambio económico y formas de administración de la propiedad rústica del Cabildo de fines del s. XIII a principios del XIV. Una aproximación», en Propiedades del cabildo segoviano, sistemas de cultivos y modos de explotación de la tierra a fines del siglo XIII, Dir. José Luis Martín, Salamanca, Universidad de Salamanca, 1981, pp. 96-207, p. 103: «... ser mas provechoso a los dichos señores dean e cabildo que non labrarlas por sy mismos ni arrendarlas por tiempos pequeños por se dexcargar de muchos trabajos e avydosos e estar mas acetos en el servicio de Dios e de la dicha yglesia non quel non podrian faser aviendo de deliberar e administrar por sy las dichas heredades e bienes». Texto tomado de Registro Antiguo de Censos, fol. 233 v. En el siglo XIV el cabildo de la catedral de Segovia señala una situación de despoblación que Ángel García Sanz atribuye al descenso de la población rural y a la violencia de los poderosos. También señala la conveniencia de arrendamientos vitalicios para despertar el entusiasmo en los arrendadores que considerarían así el bien como cosa propia.

77 IZQUIERDO BENITO, Ricardo, El Patrimonio del Cabildo de la Catedral de Toledo en el siglo XIV, Toledo, 1980, p. 263.

78 «... Les Mendiants s'étaient totalement adaptés, insérés dans le circuit économique urbain, comme bien d'autres institutions ecclésiastiques nées alors. Il fallait survivre et les revenus de cens et de rentes en étaient les meilleurs garants, à long terme. Personne ne s'y trompa, et surtout pas les «anciens Ordres», comme les Bénédictins, les Clunisiens, les Cisterciens, les Prémontrés, qui comprirent rapidement l'intérêt d'une exploitation indirecte de leur patrimoine par les mêmes procédures d'accensement et d'arrentement». BERTRAND, Paul, Commerce avec dame Pauvreté: Structures et fonctiones des couvents mendiants à Liège (XIII. ${ }^{\circ} X_{I V}{ }^{\circ} \mathrm{s}$.), Bibliothèque de la Faculté de Philosophie et Lettres de I'Université de Liège, Liège, 2004, p. 600.

79 MARTÍN PRIETO, Pablo, «Formación y evolución del patrimonio del monasterio de Santa Clara de Alcocer en la Edad Media», en Hispania Sacra, LXV, 132, junio-diciembre 2013, pp. 563-601. 
rentas fijas, será una de las características fundamentales de la economía de las clarisas de Alcocer durante el siglo $\mathrm{XVI}{ }^{80}$.

Otro monasterio de clarisas, el de Santa María la Real de Tordesillas (Valladolid), fundado en 1363, realiza desde su fundación numerosas inversiones inmobiliarias en Valladolid y Tordesillas, que inmediatamente pone en arrendamiento a fin de obtener beneficios económicos ${ }^{81}$. A partir de la segunda mitad del XV, se produce un cambio de estrategia mediante la constitución de censos, que continuará durante el siglo XVI; censos perpetuos en los arrendamientos de sus casas, que aseguraban al arrendador una renta fija perpetua ${ }^{82}$. La comunidad clarisa aplica esta modalidad de alquiler a sus posesiones vallisoletanas al menos desde 1491.

Todos los bienes raíces recibidos por el monasterio de Santa Clara la Real de Toledo a través de donaciones, son dados en arrendamiento como fórmula para tener una renta, excepto los edificios propios del convento. Las monjas se desentienden de la explotación para ser simples rentistas. Los arrendamientos de fincas urbanas son casi todos enfitéuticos y en cuanto a las fincas rústicas, la mayoría son arrendadas a matrimonios vecinos del lugar, a través de censos redimibles o al quitar ${ }^{83}$.

Por otra parte, la Orden de los Jerónimos, de vocación contemplativa y surgida en el siglo XIV, presenta una organización económica diferente ya que no emplea el sistema de granjas; en el Real Monasterio de Nuestra Señora de Fresdelval (Burgos) fundado en 1404, el cultivo de las tierras del propio monasterio y su entorno se organiza de manera directa por los monjes, y las heredades más alejadas se entregan a censo perpetuo a particulares, no habiéndose documentado ningún arrendamiento temporal por los monjes de Fresdelval ${ }^{84}$.

80 Juan de Santana, ministro franciscano de Castilla, autoriza a las Clarisas de Alcocer para enajenar cualesquiera bienes de su monasterio, con objeto de sufragar ciertas reparaciones. 1437, agosto, 4. Alcocer. El 13 de enero de 1438 la comunidad clarisa concierta un censo perpetuo sobre sus molinos de la cuesta de Gárgoles de Arriba y de la Fuente Rodera, con el concejo de Cifuentes. AHN, Clero, legajo, 1965, n.ำ 16. EX MARTIN PRIETO, Pablo, op. cit., nota 93.

${ }^{81}$ Valladolid sufrirá en esos años una importante especulación inmobiliaria. RUCQUOI, Adeline, Valladolid en la Edad Media, Valladolid, 1987.

82 Una posible razón pudo ser el deseo del Visitador de la Orden de encauzar a la comunidad hacia la estricta observancia, limitando la actividad inversora en Valladolid. RODRÍGUEZ GUILLÉN, Santiago, El monasterio de Santa María la Real de Tordesillas (1363-1509), Universidad de Alcalá, 2010.

83 «... Característica del contrato por parte del convento es establecer un trato de merced hacia el arrendatario, lo cual nos induce a pensar que estos matrimonios fueran miembros de la Orden franciscana seglar o venerable Orden Tercera. Orden religiosa, por entonces, muy extendida entre las familias castellanas...". PÉREZ DE TUDELA Y BUESO, M. a Luisa, El monasterio de Santa Clara la Real de Toledo. Estudio sobre una encomienda regia monástica (1360-1797), Universidad Complutense, 1993, p. 367.

${ }^{84}$ En 1443 entregan unas casas en el barrio de San Esteban de Burgos por un censo de $400 \mathrm{mrs}$ anuales y dos capones (AHN, Clero, carp. 220, doc. 6); en 1452 unos solares en la calle de San Juan de la misma ciudad de Diego de Alvarado por un censo anual de 85 mrs (AHN, Clero, carp. 220, doc. 15); unas tierras en Hurones se entregan en 1467 por 76 fanegas de pan mediado (AHN, Clero, carp. 221, doc. 16); las heredades de Las Quintanillas se entregan a cambio de un censo anual de 12 fanegas (AHN, Clero, carp. 222, doc. 2); en 1483 el monasterio compra en Vivar unas tierras por 12.000 mrs que entrega por un censo anual de 12 fanegas de trigo (AHN, Clero, carp. 222, doc. 10); En Ubierna recibe 


\section{CONCLUSIONES}

El paso de la explotación directa a la explotación indirecta es generalizado en la baja Edad Media y afecta tanto a los monasterios como a los conventos, las canónicas y los cabildos catedrales, independientemente del área geográfica en la que estas instituciones se hallaban ubicadas. En los casos estudiados, la causa de abandono de la explotación directa de los dominios es la pérdida de población; los propietarios de la tierra carecen de mano de obra para el cultivo de la misma por lo que se ven obligados a cederla en arrendamiento.

El factor que varía, según las distintas órdenes, es el marco cronológico en el que se produce esta transformación: en los prioratos benedictinos y en las granjas cistercienses la contracción demográfica afecta a los siervos y a los monjes conversos, respectivamente. Y se origina desde mediados del siglo XIII, produciéndose el cambio a los arrendamientos enfitéuticos, es decir, a los modos de explotación indirectos, desde el siglo XIV. La desorganización en general del poblamiento, con la escasez de mano de obra aplicable al terrazgo de libre disposición de los monjes, el encarecimiento de los salarios y la caída en desuso de las prestaciones vasalláticas parecen ser las razones que motivaron el cambio de gestión.

Sin embargo, en los monasterios premostratenses, en las canónicas, en los conventos de clarisas y en los cabildos catedrales señalados, el cambio a la explotación indirecta se produce en el siglo XIV, por lo que no resulta difícil vincular, en estos casos, la contracción demográfica y el abandono de la explotación directa con la crisis del siglo XIV. En estos monasterios y conventos se constituyen los censos enfitéuticos durante el siglo XV e incluso en algunos casos, como en Santa María de Husillos, en el siglo XVI.

En la decisión del cambio de modo de gestión directa del patrimonio monástico es indudable la influencia que tuvo el contexto histórico, marcado por la crisis demográfica y económica del siglo XIV, sin dejar de señalar, por otra parte, la mala gestión que de sus heredades hicieron los eclesiásticos en determinados casos.

La adopción del sistema de arrendamientos enfitéuticos parece responder a mentalidades que no quieren afrontar los riesgos de la explotación directa y prefieren asegurarse la percepción de unos ingresos fijos. El objetivo que buscaban los monjes era la búsqueda de seguridad, afianzando la percepción de rentas en metálico destinadas a consolidar el patrimonio monástico. La mayor parte de las rentas se estipularon en dinero, lo que redundó en beneficio del arrendatario, por

una donación de tierras en 1488 que entrega a cambio de una renta anual de 8 fanegas (AHN, Clero, carp. 222, doc. 16); ese mismo año el monasterio compra una heredad en Celada de la Torre que entrega a censo por 13 fanegas y 4 celemines anuales; (AHN, Clero, carp. 223, doc. 2). MARTíNEZ DíEZ, Gonzalo, «El monasterio jerónimo de Fresdelval. 600 años de Historia», Caja de Burgos, Burgos, 2004, pp. 54-55. 
la constante desvalorización de la moneda y el aumento del precio de los productos. Por otra parte, las cesiones de tierras contribuyeron al crecimiento agrícola beneficiando al campesinado al poner a su disposición gran número de heredades en condiciones de estabilidad.

El análisis de la evolución en la gestión de los bienes del patrimonio monástico en el caso concreto de Santa María de La Vid revela que, en general, los censos enfitéuticos fueron perjudiciales para el monasterio, al igual que para los monasterios antes reseñados, por la larga duración de los contratos que, manteniendo las condiciones a lo largo del tiempo, hicieron que los arrendadores, que en el caso vitense fueron mayoritariamente los concejos, terminaran apropiándose de las heredades monásticas y llevando a la ruina al cenobio.

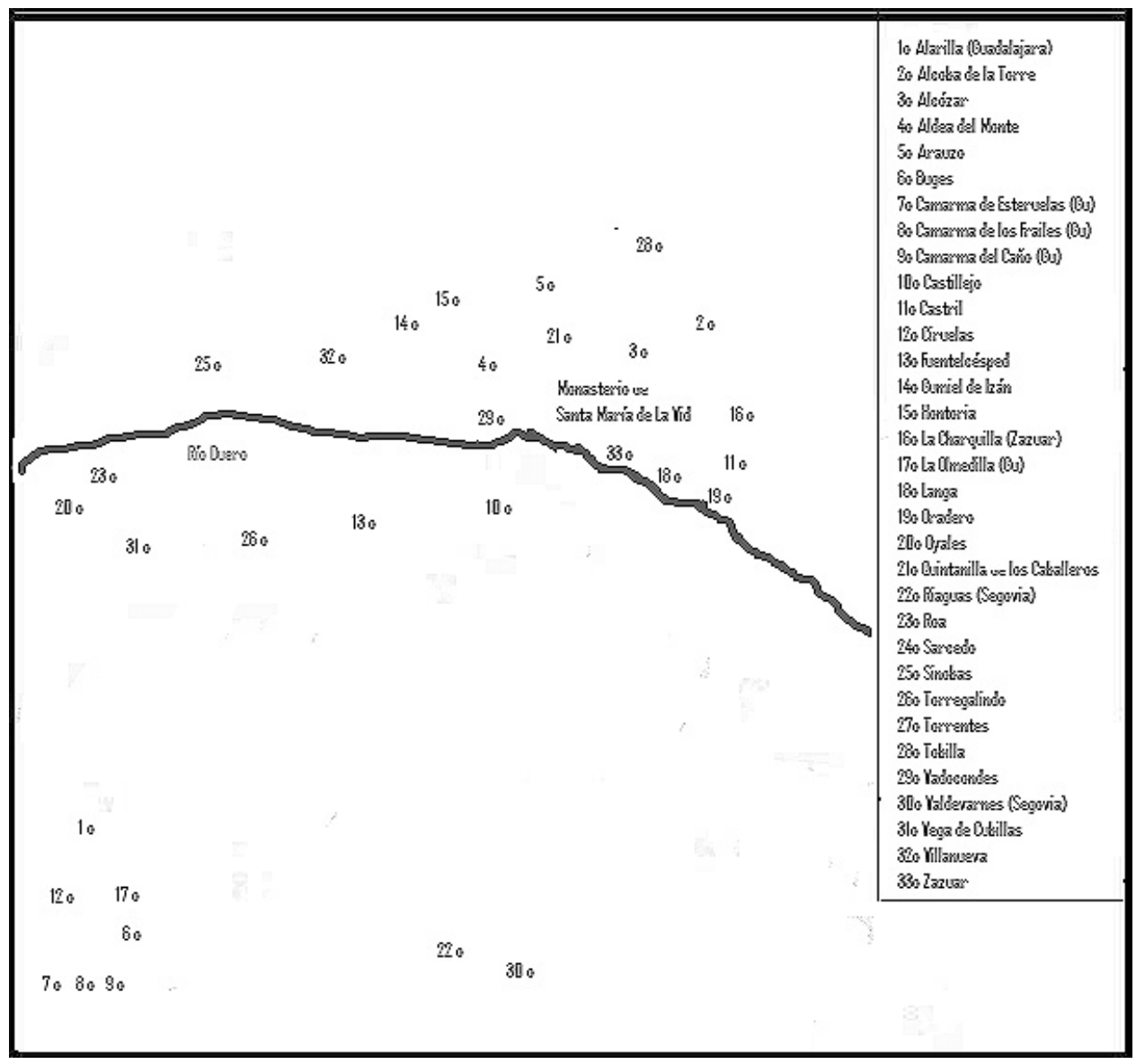

El dominio del Monasterio de Santa María de La Vid en el siglo XV 
